\title{
COVID-19: PARÂMETROS INTERNACIONAIS, FEDERALISMO E A ATUAÇÃO INTERNACIONAL DOS ESTADOS E MUNICÍPIOS
}

COVID-19: international parameters, federalism and the international operations of states and municipalities

${ }^{1}$ Universidade Estadual Paulista “Júlio de Mesquita Filho". Faculdade de Ciências Humanas e Sociais. Franca/SP, Brasil

Correspondência: Gabriela Fideles Silva. E-mail: gabriela.fideles@unesp.br

Recebido: 02/06/2020. Revisado: 19/12/2020. Aprovado: 22/12/2020. 


\section{RESUMO}

Tendo como contexto os impactos da pandemia do novo coronavírus e a relevância dada às recomendações da Organização Mundial da Saúde, este artigo buscou abordar - sob a ótica do Direito Internacional Público e das Relações Internacionais - as políticas de saúde sugeridas pelos parâmetros internacionais de enfrentamento da pandemia da COVID-19. A partir de documentos internacionais, artigos acadêmicos e informações veiculadas por meios de comunicação, analisou-se a adoção dessas políticas pelo governo federal brasileiro e por seus entes subnacionais, levando-se em conta, por fim, as ações paradiplomáticas despertadas e suas consequências para o sistema federalista brasileiro. Com base na revisão da literatura pertinente, buscou-se apresentar quais são os parâmetros internacionais que concernem à saúde; quais são os aspectos do sistema federalista brasileiro no que diz respeito à saúde; e, com base nesse estudo, qual é o efeito do federalismo na luta contra a COVID-19 e como ele pode colaborar para uma atuação cada vez maior de estados e municípios nas relações internacionais. Por fim, examinou-se a definição de paradiplomacia para se compreender o poder que os entes da União possuem no cenário internacional. Concluiu-se que os tratados e organizações internacionais têm um papel fundamental na efetivação do direito à saúde, servindo de base para que o Judiciário permita que estados e municípios tomem medidas mais restritivas no combate à COVID-19. Percebeu-se, ainda, que a falta de liderança do governo federal e a autonomia detida pelos entes federativos permitiram que estes desenvolvessem um protagonismo maior nas relações internacionais no contexto da pandemia.

Palavras-Chave: COVID-19; Federalismo; Paradiplomacia; Parâmetros Internacionais; Políticas de Saúde.

\section{ABSTRACT}

Taking as context the impacts of the new coronavirus pandemic and the relevance given to the recommendations of the World Health Organization, this article sought to address - from the perspective of Public International Law and International Relations - the health policies suggested by the international parameters for tackling the COVID-19 pandemic. Based on international documents, articles and media information, the adoption of these policies by the Brazilian federal government and its sub-national entities was analyzed, considering, finally, the paradiplomatic actions and their consequences for the Brazilian federalist system. Based on the review of the relevant literature, we sought to present what are the international parameters that concern health; what are the aspects of the Brazilian federalist system with regard to health; and, based on this study, what is the effect of federalism in the fight against COVID-19 and how it can contribute to an increasing role of states and municipalities in international relations. Finally, the definition of paradiplomacy was examined in order to understand the power of the Union entities on the international stage. It was concluded that the international treaties and organizations have a fundamental role in the effectiveness of the right to health, serving as a basis for the judiciary to allow states and municipalities to take more restrictive measures in the fight against COVID-19. It was also noticed that the lack of leadership of the federal government and the autonomy held by the federative entities allowed them to develop a greater role in international relations in the context of the pandemic.

Keywords: COVID-19; Federalism; Paradiplomacy; International Parameters; Health Policies. 


\section{Introdução}

O mundo enfrenta atualmente uma crise global de saúde que alterou o cotidiano e o modo de vida da população, gerando impactos econômicos, sociais e políticos. Segundo a Organização Mundial da Saúde (OMS), até o dia 8 de março de 2021 o mundo registrava um total de 116.363 .935 casos confirmados e 2.587.225 mortes ${ }^{1}$ em decorrência da pandemia. Trata-se da pandemia de COVID-19, doença causada pelo Sars-CoV-2, vírus da família dos coronavírus e que causa infecções respiratórias em seres humanos e em animais ${ }^{2}$. Conforme o Protocolo de Manejo Clínico, disponibilizado pelo Ministério da Saúde, a COVID-19 provoca uma síndrome respiratória aguda que varia de casos leves a casos mais graves, o que pode causar insuficiência respiratória. Sua letalidade varia de acordo com a faixa etária - por exemplo, idosos fazem parte do grupo de risco - e de condições patológicas pré-existentes - como problemas respiratórios crônicos, diabetes e doenças cardiovasculares.

A doença COVID-19, responsável pela pandemia que atingiu o mundo, teve seu epicentro em um grande mercado de frutos do mar e animais vivos em Wuhan, na China, segundo as autoridades chinesas. A transmissão inicial do vírus foi de animais, principalmente silvestres, para pessoas; entretanto, como há comprovadamente uma alta presença desse novo coronavírus em secreções respiratórias, ele passou a ser transmitido de pessoa para pessoa ${ }^{3}$.

Não é a primeira vez que a Ásia lida com um surto gerado por um coronavírus: a região tem um histórico de outras doenças graves causadas por essa família viral, como a Síndrome Respiratória Aguda Grave (SARS), identificada em 2002, e a Síndrome Respiratória do Oriente Médio (MERS), identificada em 2012. Durante o surto de SARS, a China continental e Hong Kong foram fortemente atingidas; já em 2015, a Coreia do Sul enfrentou um surto de MERS. A experiência com essas doenças fez com que alguns países asiáticos tivessem êxito na resposta à atual pandemia. Graças a medidas imediatas e a informações à população sobre as formas de prevenção e a gravidade da doença, esses países se destacam pela coesão nas ações adotadas.

\footnotetext{
${ }^{1}$ Dados atualizados em 08 de março de 2021, após aprovação do artigo para publicação.

${ }^{2}$ MINISTÉRIO DA SAÚDE - MS. Protocolo de Manejo Clínico do coronavírus (COVID-19) na Atenção Primária à Saúde. Versão 9. Brasília-DF: Secretaria de Atenção Primária à Saúde (SAPS), 2020. Disponível em: https:// portalarquivos2.saude.gov.br/images/pdf/2020/May/05/20200504-ProtocoloManejo-ver09.pdf. Acesso em: 16 fev. 2021..

${ }^{3}$ MINISTÉRIO DA SAÚDE - MS. Plano de Contingência Nacional para Infecção Humana pelo novo coronavírus COVID-19. Brasília-DF: Secretaria de Vigilância em Saúde, 2020. Disponível em: https://portalarquivos. saude.gov.br/images/pdf/2020/marco/25/Livreto-Plano-de-Contingencia-5-Corona2020-210x297-16mar. pdf. Acesso em: 16 fev. 2021.
} 
A Emergência de Saúde Pública de Importância Internacional (ESPII), decretada pela OMS em 30 de janeiro de $2020^{4}$ por conta do potencial de transmissão do vírus, ancorou-se no Regulamento Sanitário Internacional (RSI) ${ }^{5}$ - instrumento jurídico de 2005 que vincula 196 países-membros da OMS e trata dos direitos e obrigações dos Estados frente a eventos de saúde pública, desde a prevenção da propagação de doenças até a vigilância e a resposta às emergências de saúde. Já a pandemia de COVID-19 foi decretada pela OMS no dia 11 de março de 2020, como pode ser visto no pronunciamento da Organização Pan-Americana da Saúde (OPAS) ${ }^{6}$.

Desde então, muitos esforços têm sido feitos para a mitigação dos efeitos da doença na população. Dentre as políticas públicas de combate à COVID-19 mais comumente tomadas pelos Estados estão o isolamento social e a testagem da população para quantificar a contaminação. Contudo, alguns países passam por uma disputa política sobre como lidar com a crise provocada pela pandemia.

Em alguns Estados federativos, está havendo um embate de forças entre os entes subnacionais - que têm maior autonomia de ação e decisão do que em nações que adotaram o sistema de federação - e o governo federal. Países como Estados Unidos e Brasil passam por divergências entre seus respectivos entes federativos e governos centrais no que diz respeito a resposta à crise internacional instaurada. Em ambos os países, a maioria dos governadores e prefeitos toma medidas mais restritivas e com um discurso mais firme no enfrentamento da pandemia, entrando em descompasso com os presidentes. Em seus discursos, os chefes do executivo demonstram grande preocupação com os reflexos da crise na economia, mas adotam um tom mais ameno sobre a gravidade da doença - tecendo críticas à OMS e adotando algumas posturas que vão na contramão de recomendações ministeriais e da OMS .

Percebe-se, portanto, que a discussão do papel dos entes federativos nas relações internacionais, na política externa e na diplomacia é de suma importância atualmente. Desta forma, este trabalho pretende analisar como os parâmetros internacionais auxiliam a tomada de decisões de saúde no Brasil, principalmente no contexto de disputas entre os entes da União na pandemia, por conta do sistema federalista brasileiro.

\footnotetext{
${ }^{4}$ OMS declara emergência de saúde pública de importância internacional por surto de novo coronavírus. OPAS Brasil, 30 jan. 2020. Disponivel em: https://www.paho.org/bra/index.php?option=com_content\&vie $\mathrm{w}=$ article\&id=6100:oms-declara-emergencia-de-saude-publica-de-importancia-internacional-em-relacao-anovo-coronavirus\&ltemid=812. Acesso em: 16 fev. 2021.

${ }^{5}$ ORGANIZAÇÃO PAN-AMERICANA DA SAÚDE - OPAS. Regulamento Sanitário Internacional (RSI). Disponivel em: https://www.paho.org/bra/index.php?option=com_content\&view=article\&id=5847:regulamento-sanitario-int ernacional-rsi\&ltemid=812. Acesso em: 16 fev. 2021.

${ }^{6}$ OMS afirma que COVID-19 é agora caracterizada como pandemia. OPAS Brasil, 11 mar. 2020. Disponivel em: https://www.paho.org/bra/index.php?option=com_content\&view=article\&id=6120:oms-afirma-que-covid-19-eagora-caracterizada-como-pandemia\&ltemid=812. Acesso em: 16 fev. 2021.

${ }^{7} \mathrm{O}$ artigo foi elaborado e avaliado durante o ano de 2020, quando o presidente da República dos Estados Unidos era Donald Trump.
} 
Em vista disso, serão apresentados alguns tratados, recomendações e organizações internacionais relacionados à saúde, além de literatura sobre o tema, que servem de base para a tomada de decisões. Em seguida, este artigo buscará tratar sobre o sistema federativo brasileiro e os conflitos de decisões que provoca, demonstrando como os parâmetros internacionais auxiliam a solução das controvérsias nesse sentido. Por fim, serão abordadas algumas questões sobre o aumento de ações paradiplomáticas na pandemia - buscando defini-las e apontando alguns exemplos - a fim de mostrar que estão relacionadas também a conflitos e divergências dos entes federativos, concluindo que as ações dos estados e municípios, em grande parte das vezes, têm sido mais protetivas à saúde e amparadas pelos parâmetros internacionais.

\section{Parâmetros internacionais e legislação brasileira}

Em um momento de instabilidade, como o vivenciado com a pandemia do novo coronavírus, muito se questiona sobre como os países devem responder e agir. Além disso, entram em debate os direitos sociais da população, como a saúde, e quais são as implicações jurídicas envolvidas. Nesse sentido, Borges ${ }^{8}$ afirma que os tratados internacionais em matéria de saúde ajudam a aclarar o alcance e o sentido dos direitos sociais. Ademais, as resoluções e recomendações emitidas por organizações internacionais trazem diretrizes mais claras e precisas sobre as medidas que devem ser tomadas pelos Estados.

No âmbito dos direitos humanos, a saúde é um componente essencial para o desenvolvimento sustentável dos povos, sendo um direito assegurado pela Declaração Universal dos Direitos Humanos. Encontra-se em seu artigo 25: “Todo ser humano tem direito a um padrão de vida capaz de assegurar a si e à sua família saúde, bem-estar [...]"9. Para além do descrito, o tema de saúde também é abordado nos 17 Objetivos de Desenvolvimento Sustentável (ODS) ${ }^{10}$, fixados em 2015 pela ONU como um plano de ação até 2030 para garantir aos povos e ao planeta o desenvolvimento com qualidade e sustentabilidade. Essa agenda deixa evidente o papel estatal de buscar meios e desenvolver políticas públicas que visem a garantir e promover o bem-estar e a qualidade de vida para sua população.

As bases para o processo de construção dos objetivos universais de desenvolvimento sustentável foram estabelecidas na Conferência Rio+20 e, conforme

\footnotetext{
${ }^{8}$ BORGES, Daniel Damásio. O alcance dos tratados sobre os direitos sociais no direito brasileiro. 1. ed. Curitiba: Editora Appris, 2019.

${ }^{9}$ ORGANIZAÇÃO DAS NAÇÕES UNIDAS - ONU. Declaração Universal dos Direitos Humanos. Adotada e proclamada pela Assembleia Geral das Nações Unidas (resolução 217 A III) em 10 de dezembro 1948. Disponível em: https://www.unicef.org/brazil/declaracao-universal-dos-direitos-humanos. Acesso em: 16 fev. 2021.

${ }^{10}$ PROGRAMA DAS NAÇÕES UNIDAS PARA O DESENVOLVIMENTO. Plataforma Agenda 2030. Disponível em: http://www.agenda2030.com.br/. Acesso em: 16 fev. 2021.
} 
Buss $^{11}$, a área de saúde teve um espaço específico e muito importante no documento final produzido na conferência. Outro parâmetro internacional de destaque para a proteção da saúde é o Pacto Internacional de Direitos Econômicos, Sociais e Culturais $^{12}$ (PIDESC), adotado em 1966 pela Assembleia Geral das Nações Unidas. O documento reconhece os direitos inerentes à pessoa humana e coloca como dever do Estado garantir a proteção dos direitos econômicos, sociais e culturais, assim como os direitos civis e políticos, descritos no Pacto. O PIDESC define a saúde não apenas como a ausência de doença, mas como o "direito de toda pessoa de desfrutar o mais elevado nível possível de saúde física e mental"13.

Para acompanhar e promover a efetivação do direito à saúde no âmbito internacional, tem-se a OMS, possuidora do propósito de reduzir os efeitos das situações emergenciais de saúde dos povos juntamente com os Estados, além de fomentar a prevenção de agravos à saúde, a mitigação desses agravos e a preparação de diferentes atores para atuar frente às ocorrências que afetem o bem-estar dos indivíduos. Para alcançar seus objetivos, ela trabalha majoritariamente com recomendações e resoluções, que não têm caráter vinculante, diferentemente do que ocorre com o RSI. Ou seja, os Estados não são obrigados a acatar as recomendações emitidas pela OMS, como vem ocorrendo em alguns poucos países do mundo no que tange ao novo coronavírus; em contrapartida, os Estados devem acatar os artigos descritos no RSI, por possuir caráter vinculativo. No contexto da emergência causada pela pandemia, foi ressaltado o artigo 44, que trata do apoio mútuo, cooperação e compartilhamento de informações para identificação do vírus; e o artigo 43, que trata da implementação de medidas que afetam o tráfego internacional.

A resposta à COVID-19 se dá nos marcos do RSI, cujas proposições incluem evitar a propagação global de doenças infecciosas - e uma das consequências disso é a interrupção nas relações comerciais internacionais com vistas à segurança sanitária mundial. A nova abordagem, que entrou em vigor em 2007, após a revisão do regulamento feita em 2005, visa a orientar o combate e a resposta, por parte dos Estados-membros, às emergências de saúde pública, compartilhando informações acerca de medidas a serem tomadas frente aos riscos à saúde. O RSI, por fim, apresenta avanços nas áreas de fortalecimento de sistemas nacionais e de mecanismos de vigilância internacional.

A OMS, no entanto, vem sofrendo nos últimos anos com o subfinanciamento por parte de Estados cujos líderes adotam um viés que se assemelha ao

${ }^{11}$ BUSS, Paulo M. De pandemias, desenvolvimento e multilateralismo. Le Monde Diplomatique Brasil, 03 abr. 2020. Disponível em: https://diplomatique.org.br/de-pandemias-desenvolvimento-e-multilateralismo/. Acesso em: 14 maio 2020..

${ }^{12}$ BRASIL. Decreto n. 591, de 6 de julho de 1992. Atos Internacionais. Pacto Internacional sobre Direitos Econômicos, Sociais e Culturais. Promulgação. Disponível em: http://www.planalto.gov.br/ccivil_03/ decreto/1990-1994/d0591.htm. Acesso em: 16 fev. 2021.

${ }^{13}$ BORGES, Daniel Damásio. O alcance dos tratados sobre os direitos sociais no direito brasileiro, cit., p. 72. 
nacionalismo e ao populismo. Esses líderes nacionais têm a tendência de desmobilizar os mecanismos multilaterais de cooperação e enfraquecer as organizações internacionais. No contexto da pandemia, por exemplo, o governo de Donald Trump decidiu retirar o financiamento da OMS e chegou a anunciar a saída dos Estados Unidos da organização ${ }^{14}$.

No caso brasileiro, mais especificamente, as condutas tomadas pelo presidente Jair Bolsonaro no gerenciamento da crise - como a negação da gravidade da doença, o incentivo ao uso de medicamentos que ainda não tiveram sua eficácia comprovada, críticas a governadores e prefeitos que adotaram medidas de isolamento, dentre outras ${ }^{15}$ - criaram um vazio de liderança, abrindo espaço para que os governadores e prefeitos a assumissem. Muitos destes adotaram medidas em sintonia com as recomendações da OMS para lidar com a COVID-19, preenchendo, assim, o vazio deixado pelo governo federal.

Essa posição contrária ao isolamento social e a outras medidas mais protetivas à saúde, adotada principalmente por líderes populistas, vai ao encontro da hipótese defendida por Agamben, que cunhou o termo a "invenção epidêmica"16. Com uma abordagem biopolítica para argumentar sua posição acerca da COVID-19, o autor entende esse conceito a partir de uma visão de que a "vida natural" ou "vida nua" dos indivíduos estaria sob o controle do Estado, poder soberano, que se utilizaria, para este fim, de técnicas de controle e mecanismos de normalização da vida nua para dominação ${ }^{17}$. No artigo "A invenção de uma epidemia”, publicado em fevereiro de 2020 no site da editora Quodlibet, Agamben aponta que as medidas sanitárias emergenciais adotadas pelo governo italiano seriam desproporcionais e injustificadas. O autor afirma que o Estado, juntamente com a mídia, estaria se utilizando do temor do contágio para restringir liberdades, seguindo sua lógica de biopoder e das formas de controle pelo Estado para limitação do indivíduo ${ }^{18}$.

Entretanto, a visão de Agamben não leva em conta o alto nível de contágio do vírus e, consequentemente, seu grau de letalidade. Medidas restritivas são um meio de garantir a segurança da população, preservar a vida e evitar a saturação dos sistemas de saúde. Uma possível contraposição aos argumentos apresentados é a de Habermas, que em suas entrevistas traz uma outra visão sobre as medidas

${ }^{14}$ TRUMP suspende financiamento dos Estados Unidos à OMS. O Estado de S. Paulo, São Paulo, 14 abr. 2020. Disponível em: https://internacional.estadao.com.br/noticias/geral,trump-suspende-financiame nto-dos-estados-unidos-a-oms,70003271069. Acesso em: 07 maio 2020.

${ }^{15}$ ABRANTES, Vinicius Villani. Brasil e a "diplomacia da saúde": um recorte temporal da atuação do estado na pandemia de COVID-19. Boletim de Conjuntura, ano II, vol. 4, n. 10, Boa Vista, 2020.

${ }^{16}$ GUEDES, Jozivan. Biopolítica e normatividade: duas abordagens filosóficas acerca da pandemia da COVID-19 a partir de Agamben e Habermas. Voluntas: revista internacional de filosofia, v. 11, e8, p. 1, 2020. Disponível em: https://periodicos.ufsm.br/voluntas/article/download/43663/pdf. https://doi. org/10.5902/2179378643663.

${ }^{17} / d$. Ibid., p. 2.

18/d. Ibid., p. 3. 
de isolamento adotadas pelos países. De acordo com o filósofo e sociólogo alemão, "os direitos fundamentais proíbem os órgãos estatais de tomar qualquer decisão que aceite a possibilidade de morte dos indivíduos"19, e o que deve ser pautado é a intangibilidade da dignidade humana.

Habermas afirma que é dever do Estado proteger e respeitar os direitos humanos e coloca dois pontos principais de preocupação: as triagens, referindo-se à superlotação e à escassez de unidades de terapia intensiva (UTI), o que obriga os médicos a tomarem a difícil decisão de quem terá acesso a elas; e o correto momento para encerrar o isolamento social, medida que, segundo ele, é "moral e legalmente exigida para a proteção da vida" ${ }^{20}$. Para o autor, não se deve ceder às demandas do mercado para reiniciar mais rápido a economia, colocando em risco a vida da população com a sobrecarga do sistema de saúde e o aumento da taxa de mortalidade.

Além disso, Habermas argumenta que as medidas sanitárias são importantes e devem ser tomadas para a manutenção da vida seguindo os aspectos éticos, de forma que:

[...] a limitação de um grande número de liberdades importantes deve permanecer uma exceção estritamente contida. Mas a exceção é em si mesma, como acabei de demonstrar, exigida pelo direito primário à proteção da vida e da integridade física"21 .

No que diz respeito às medidas de distanciamento e isolamento social estabelecidas por diferentes entes federativos - tais como a suspensão de atividades presenciais de ensino, as restrições às atividades comerciais e à circulação de pessoas -, o ministro Alexandre de Moraes, do Supremo Tribunal Federal (STF), reconheceu e assegurou o exercício da competência concorrente dos governos estaduais, distritais e municipais, permitindo que estes adotem medidas mais restritivas quando acharem necessário ${ }^{22}$, baseando-se nas políticas adotadas ao redor do mundo e, principalmente, nas recomendações da OMS.

Essa prerrogativa dada a governadores e prefeitos para a tomada de decisão e implementação de leis não é um caso inédito nem revolucionário, mas sim jurisprudencial. Um precedente é a decisão do STF no caso do amianto - mineral fibroso cujas fibras, quando inaladas, podem causar "sérios problemas de saúde, tais como

\footnotetext{
${ }^{19} \mathrm{~A}$ SOLIDARIEDADE é a única cura. Entrevista com Jürgen Habermas. Revista IHU On-Line, 13 abr. 2020. Disponível em: http://www.ihu.unisinos.br/78-noticias/597983-a-solidariedade-e-a-unica-cura-entre vista-com-juergen-habermas. Acesso em: $10 \mathrm{dez} .2020$.

${ }^{20} / d$. Ibid.

${ }^{21} / d$. Ibid.

${ }^{22}$ SUPREMO TRIBUNAL FEDERAL - STF. Arguição de Descumprimento de Preceito Fundamental n. 672 , de 15 maio de 2020. Disponível em: https://www.stf.jus.br/arquivo/cms/noticiaNoticiaStf/anexo/ ADPF672liminar.pdf. Acesso em: 16 fev. 2021.
} 
a asbestose, o mesotelioma e o câncer do pulmão"23 - pela constitucionalidade de uma lei estadual de São Paulo que proibia a comercialização do produto, indo contra uma lei federal que a permitia. A decisão justificou a constitucionalidade da lei paulista apontando a Convenção n. 162 da Organização Internacional do Trabalho $(\mathrm{OIT})^{24}$ como norma protetora de direitos fundamentais e, dessa forma, do direito à saúde e ao meio ambiente equilibrado. Tal decisão também foi pautada no direito à saúde conforme definido da DUDH e no PIDESC, além de estar alinhada com as diretrizes mais precisas da OMS.

A União, conforme Arretche ${ }^{25}$, é a responsável por formular e financiar a política nacional de saúde, devendo coordenar as ações intergovernamentais. Como estabelece a Constituição Federal de $1988(\mathrm{CF} / 88)^{26}$, devem existir na federação uma cooperação e uma articulação do Estado e os entes subnacionais, principalmente nas áreas em que estes entes podem atuar, como é o caso da saúde.

Não obstante, conforme Borges ${ }^{27}$, o Estado federativo brasileiro prevê que estados e municípios detenham o poder de legislar e executar políticas sociais, já que possuem independência por serem entes federativos autônomos, visando principalmente ao interesse local de desenvolvimento. Entretanto, para que não haja sobreposição de normas, é necessário que o governo federal se articule com governos estaduais e municipais para que todos atuem de modo concertado e coerente. Borges conclui que não há uma articulação evidente na formulação e implementação de políticas públicas pelas diferentes esferas do poder público. É importante ressaltar que:

[...] as convenções internacionais sobre saúde passam a ser um dos critérios determinantes para a apreciação da constitucionalidade de leis estaduais sobre esse tema. Nessa linha de considerações, se tais leis estaduais estipularem parâmetros de proteção à saúde mais rígidos e que estejam em conformidade com convenções internacionais, a sua constitucionalidade deve ser reconhecida, ainda que contrariem leis federais sobre o mesmo tema ${ }^{28}$.

Mais uma vez, os estados e municípios têm tomado medidas mais protetivas à saúde do que o governo federal, na conjuntura da pandemia de COVID-19. Dentre essas medidas, estão o plano de prevenção desenvolvido pelo governo

\footnotetext{
${ }^{23}$ BORGES, Daniel Damásio. O alcance dos tratados sobre os direitos sociais no direito brasileiro, cit., p. 78. ${ }^{24}$ ORGANIZAÇÃO INTERNACIONAL DO TRABALHO - OIT. C162 - Utilização do Amianto com Segurança. Disponivel em: https://www.ilo.org/brasilia/convencoes/WCMS_236241/lang--pt/index.htm. Acesso em: 16 fev. 2021.

${ }^{25}$ ARRETCHE, Marta. Federalismo e políticas sociais no Brasil: problemas de coordenação e autonomia. São Paulo Perspectiva, São Paulo, v. 18, n. 2, p. 17-26, abr./jun. 2004. Disponível em: https://www.scielo.br/ pdf/spp/v18n2/a03v18n2.pdf. https://doi.org/10.1590/S0102-88392004000200003.

${ }^{26}$ BRASIL. Constituição da República Federativa do Brasil de 1988. Disponível em: http://www.planalto.gov. br/ccivil_03/constituicao/constituicaocompilado.htm. Acesso em: 16 fev. 2021.

${ }^{27}$ BORGES, Daniel Damásio. O alcance dos tratados sobre os direitos sociais no direito brasileiro, cit.

${ }^{28}$ Id. Ibid., p. 90-91.
} 
estadual de São Paulo e as campanhas de comunicação de orientação ${ }^{29}$ e prevenção ao novo coronavírus no estado, em consonância com as recomendações da OPAS/ $\mathrm{OMS}^{30}$ - inclusive a de "comunicação de risco e engajamento comunitário", para manter a qualidade de informações e a confiança da população, incentivando seu engajamento nas medidas propostas.

Essa liberdade assumida pelos entes subnacionais regionais e municipais para tomar decisões acerca de medidas para prevenção e enfrentamento da COVID-19, respaldada pelo Judiciário, fez com que eles exercessem um papel maior também nas relações internacionais. Os governadores e prefeitos, no contexto da pandemia, passaram a desenvolver ações paradiplomáticas pontuais visando a satisfazer as necessidades de seus respectivos estados e municípios que não forem atendidas pelo governo federal, como a compra de insumos variados (anestésicos para intubação, respiradores, oxigênio etc.) e de equipamentos de proteção individual.

\section{Paradiplomacia}

Para entender qual é o papel da paradiplomacia na atual crise sanitária e qual é sua possibilidade de auxiliar os entes federativos no enfrentamento da COVID-19, é necessário compreender o significado do termo. Há diversas formas de abordar a paradiplomacia, o que se dá, entre outros fatores, por sua evolução de uma política pontual, nos anos 1960, para uma política institucionalizada stricto sensu. Para Romero ${ }^{31}$, o envolvimento subnacional já é, de fato, uma questão estrutural do sistema político internacional.

Por causa da globalização, segundo Ribeiro ${ }^{32}$, questões como saúde pública, comunicação, transporte, organização do território, cultura e serviços sociais, que são tradicionalmente competências dos governos federais, têm sido flexibilizadas pela conjuntura internacional e impactado diretamente o cenário local, cabendo, assim, aos governos das esferas estadual e municipal agir. Ou seja, a globalização favoreceu a participação dos entes subnacionais como atores nas relações internacionais.

${ }^{29}$ SAIBA quais as medidas do Governo de SP para o combate ao coronavírus. Portal do Governo, 17 mar. 2020. Disponível em: https://www.saopaulo.sp.gov.br/spnoticias/saiba-quais-as-medidas-do-governo-de-sp-para-ocombate-ao-coronavirus-2/. Acesso em: 16 fev. 2021.

${ }^{30}$ FOLHA informativa - COVID-19 (doença causada pelo novo coronavírus). OPAS Brasil, 12 fev. 2021. Disponivel em: https://www.paho.org/bra/index.php?option=com_content\&view=article\&id=6101:covid1 9\&Itemid=875\#datas-noticificacoes. Acesso em: 16 fev. 2021.

${ }^{31}$ DEL HUERTO ROMERO, Maria. Poder local y relaciones internacionales en contextos de integración regional: el caso de la red de mercociudades y la reunion especializada de municípios e intendencias: Grupo Mercado Comum. In: VIGEVANI, Tullo; WANDERLEY, Luiz Eduardo W.; BARRETO, Maria Inês; MARIANO, Marcelo Passini (Orgs.). A dimensão subnacional e as relações internacionais. 1. ed. São Paulo: Editora UNESP; Bauru: EDUSC, 2004.

${ }^{32}$ RIBEIRO, Maria Clotilde Meirelles. Globalização e novos atores: a paradiplomacia das cidades brasileiras. Salvador: Editora da UFBA, 2009. 
Informalmente, a paradiplomacia pode ser definida como a política externa de um nível de governo não central. Embora tal afirmação ajude a dar uma ideia geral, não se pode basear somente nela, pois muito se discute se os entes subnacionais podem ser considerados atores internacionais e se possuem prerrogativa de formulação e de ação em política externa. A doutrina clássica do Direito sugere a coerência/unidade da política externa, e o Direito Internacional Público considera somente o Estado como sujeito do Direito Internacional, por exemplo.

Assim, a paradiplomacia

[...], refere-se à participação dessas unidades, independente do Estado central, na busca de seus próprios interesses na arena internacional. Também é apresentada como uma atividade com a função de integração e de cooperação [...]. Nessa linha de argumentação, propõe-se uma descentralização da política externa, na qual o governo central atuaria como coordenador da ação externa de suas unidades, de forma a garantir uma harmonia entre todos os Estados subnacionais e deles com a política nacional para o plano externo [...]. Alguns autores registram um tipo particular de paradiplomacia: a protodiplomacia, que seria um ativismo político segundo o qual governos locais buscam apoio internacional para causas independentistas ${ }^{33}$.

A ação paradiplomática é mais forte nos regimes federais ou com estruturas descentralizadas do que em regimes centralizados. Para Hocking ${ }^{34}$, essa ação pode se dar tanto diretamente no sistema internacional (protagonista), quanto indiretamente (mediadora), exercendo influências nos governos nacionais.

Os mecanismos e ferramentas mais comuns usados por governos locais são: twinning (cooperação bilateral entre dois governos locais); intercâmbio de boas práticas de gestão urbana; declaração de um município como livre de armas nucleares ou como santuário de refugiados; engajamento em redes internacionais (voltadas a intensificar e consolidar processos de integração regional com um foco temático bem definido - meio ambiente, por exemplo); colaboração em programas de cooperação técnica; e inserção em associações municipais.

Já os governos regionais se valem de: escritórios offshore permanentes; realização de missões governamentais conduzidas por líderes de grupos não centrais (GNCs); realização de missões profissionais para assuntos específicos; participação

\footnotetext{
${ }^{33}$ ABREU, Gustavo de Souza. Efeitos político-jurídicos da não institucionalizada paradiplomacia no Brasil. Revista Brasileira de Políticas Públicas, Brasília, v. 3, n. 2, p. 69, 2013. Disponível em: https://www. publicacoes.uniceub.br/RBPP/article/download/1803/pdf_1. https://doi.org/10.5102/rbpp.v3i2.1803.

${ }^{34}$ HOCKING, Brian. Regionalismo: uma perspectiva das relações internacionais. In: VIGEVANI, Tullo; WANDERLEY, Luiz Eduardo W.; BARRETO, Maria Inês; MARIANO, Marcelo Passini (Orgs.). A dimensão subnacional e as relações internacionais. 1. ed. São Paulo: Editora UNESP; Bauru: EDUSC, 2004.
} 
em feiras e exposições internacionais; estabelecimento de zonas de livre comércio; participação de representantes do GNC em conferências internacionais ou comitivas diplomáticas oficiais ou manutenção de adidos internacionais em embaixadas.

A paradiplomacia, quando bem institucionalizada e condizente com as diretrizes da política externa do país e havendo coordenação entre os entes subnacionais, fortaleceria a democracia e o sistema federa ${ }^{35}$, contribuindo para o desenvolvimento local e, consequentemente, nacional. Já quando ela não é bem institucionalizada, os riscos de desalinhamento evidenciam uma possível atitude política à revelia das estratégias do governo central. No plano histórico brasileiro, encontram-se situações nas quais o desacordo radical com o governo central estimulou a ação internacional dos estados com consequências desestabilizadoras ${ }^{36}$.

Os dois principais gatilhos paradiplomáticos brasileiros seriam: a desigualdade econômica existente entre regiões e estados da federação; e os estímulos que o novo sistema internacional dá para a participação direta do poder local nas relações internacionais ${ }^{37}$ - democratizando-as, de certa forma. É possível, também, listar as maiores dificuldades enfrentadas pela paradiplomacia, dada a pouca relevância que lhe é dada; as restrições de recursos financeiros dos estados; a fragmentação das ações de relações internacionais realizadas pelos órgãos municipais; e a falta de autonomia dos municípios.

O trato de questões internacionais de jure é de competência da União (CF/88, art. 21, I), cabendo ao presidente da República celebrar tratados e convenções internacionais (CF/88, art. 84, VIII); ao Congresso Nacional resolver sobre tais tratados e acordos internacionais (CF/88, art. 49, I); e ao Senado Federal autorizar ações financeiras internacionais. Seguindo essa linha de pensamento, Salomón e Nunes ${ }^{38}$ diferenciam os atores: os governos locais e os entes subnacionais regionais são "livres de soberania" e o governo central, "condicionado pela soberania".

Dos argumentos apresentados anteriormente, é possível afirmar que há um descompasso jurídico acerca de ações internacionais por parte de estados federados e municípios. Esforços importantes nesse sentido foram empregados, podendo ser citada a Proposta de Emenda Constitucional da Paradiplomacia (PEC n. 475/2005), além de uma Proposta Legislativa (PL do Senado n. 98). Porém, ambas as propostas foram arquivadas, pois seu conteúdo foi entendido como inconstitucional. Em

\footnotetext{
${ }^{35}$ RIBEIRO, Maria Clotilde Meirelles. op. cit., p. 36.

${ }^{36}$ VIGEVANI, Tullo; PRADO, Débora Figueiredo B. Ações e problemas para a paradiplomacia no Brasil. In: BLANES SALA, José; GASPAROTO, Ana Lúcia (Orgs.). Relações internacionais: polaridades e novos/velhos temas urgentes. Marília-SP: Editora UNESP - Oficina Universitária, 2010.

${ }^{37}$ RIBEIRO, Maria Clotilde Meirelles. op. cit.

${ }^{38}$ SALOMÓN, Mónica; NUNES, Carmen. A ação externa dos governos subnacionais no Brasil: os casos do Rio Grande do Sul e de Porto Alegre. Um estudo comparativo de dois tipos de atores mistos. Contexto Internacional Rio de Janeiro, vol. 29, n. 1, p. 99-147, jan./jun. 2007. Disponível em: https://www.scielo.br/ pdf/cint/v29n1/a04v29n1.pdf. https://doi.org/10.1590/S0102-85292007000100004.
} 
1997, também foi criada a Assessoria de Relações Federativas (ARF), vinculada ao gabinete do ministro das Relações Exteriores e que mais tarde se tornou Assessoria para Assuntos Federativos e Parlamentares (AFEPA), cujo objetivo melhorar é a captação dos interesses dos estados na formulação da política externa.

No entanto, tais esforços não foram suficientes para reverter o problema jurídico que a paradiplomacia causa ao Estado brasileiro. Este se opõe à institucionalização porque teme perder sua soberania, muito embora seja tolerante a seu exercício; agindo dessa forma, ele incita, paradoxalmente, o fomento do procedimento à margem da lei que pode justamente comprometer seu poder soberano ${ }^{39}$.

Vale trazer aqui a visão de Kugelmas e Branco (2004 apud VIGEVANI, 2004), segundo a qual duas forças convivem e combatem na relação entre o governo central e os poderes locais: uma, centrípeta, procuraria reter o poder para o governo central, permitindo ações autônomas das unidades subnacionais desde que as regulando e as controlando; outra, centrífuga, mostraria as unidades subnacionais em busca de maior autonomia política e econômica para garantir seus interesses específicos, tendência esta acentuada atualmente pelas crescentes assimetrias na distribuição de recursos internos e nas oportunidades de negócios abertas em decorrência da globalização econômica. Desta forma, a distorção resultante do desequilíbrio federativo a partir da concentração de fatores produtivos, industriais, de serviços e tecnologia, numa região do país em detrimento de outras, além da concentração populacional, na visão destes autores, poderia fortalecer os elementos centrífugos na relação entre o governo central e os poderes locais ${ }^{40}$.

Para um melhor diálogo e uma tentativa de solução ao impasse jurídico da paradiplomacia, esta deveria ser entendida como um instrumento estatal para o desenvolvimento de políticas públicas, visando a colocar em prática ou facilitar o alcance dos objetivos fundamentais do Brasil, descritos na Carta Magna $(\mathrm{CF} / 88$, art. $3^{\circ}$, I e II).

A ação paradiplomática no Brasil, enfim, é muito marcada pelas ações dos líderes políticos, uma vez que é pragmática em casos de ineficiência do governo federal. Tal estratégia é conhecida como stop and go; em síntese, é aquela ação que recorre ao cenário internacional visando a solucionar questões vinculadas a necessidades locais, marcada por objetivos subjetivos e específicos. Tal ação não responderia a estratégias definidas, mas sim às necessidades dos governos subnacionais em uma determinada questão.

\footnotetext{
${ }^{39}$ ABREU, Gustavo de Souza. op. cit., p. 66-79.

${ }^{40}$ RIBEIRO, Maria Clotilde Meirelles. op. cit., p. 108.
} 


\section{Atuação internacional brasileira e a COVID-19}

A adoção das resoluções e recomendações de organizações e tratados internacionais por parte dos entes federativos, somada à paradiplomacia, permite e auxilia a implementação de políticas públicas regionais e locais, indo ao encontro do interesse regional e/ou local. Estas políticas públicas satisfazem também os compromissos internacionais firmados pelo Estado brasileiro citados anteriormente, como os Objetivos de Desenvolvimento Sustentável (ODS).

Dentro desses parâmetros internacionais que colaboram para a inserção dos entes subnacionais no cenário internacional e na elaboração e aplicação de políticas públicas, têm-se, no contexto da pandemia, as recomendações publicadas pela OMS - políticas mais restritivas de circulação e aglomeração, com o fechamento de escolas e centros comerciais - sendo acatadas por grande parte dos entes subnacionais para a proteção da população e o enfrentamento da COVID-19.

É notável, portanto, no contexto de pandemia, o caráter de soft law das recomendações da OMS, possuidoras de efeito quase vinculante e de um alto nível de adesão. O Direito Internacional Público entende soft law como expressão que designa regras que ainda não se tornaram obrigatórias - por exemplo, recomendações publicadas por organizações internacionais e declarações finais de conferências internacionais - bem como regras que já se tornaram obrigatórias, porém foram formuladas de maneira imprecisa e vaga - por exemplo, declarações de princípios.

Entre as ações paradiplomáticas adotadas no Brasil no início da pandemia, está o movimento realizado por 11 governadores - dos nove estados do Nordeste, do Pará e do Distrito Federal - que entraram em contato diretamente com a embaixada chinesa em Brasília para tentar obter insumos necessários e discutir planos estratégicos de combate à pandemia, com a justificativa de não estarem satisfeitos com o governo central ${ }^{41}$. Outra ação paradiplomática nesse período foi uma carta redigida por 43 prefeitos do Rio Grande do Sul, todos membros da Associação dos Municípios da Zona de Produção (AMZOP), e enviada ao embaixador chinês Yang Wanming pedindo assistência referente a materiais médicos, insumos e medicamentos. A carta ressalta que, em missão no território chinês em 2018, os prefeitos da AMZOP e o Estado chinês haveriam estreitado suas relações ${ }^{42}$. Demonstra-se, assim, a instrumentalização das redes municipais em âmbito internacional e das missões governamentais conduzidas por líderes do GNC. O próprio diretor-executivo do Programa de Emergências em Saúde da OMS, Michael Ryan, declarou em coletiva

\footnotetext{
${ }^{41}$ BENITES, Afonso. Desconfiados de Bolsonaro, governadores recorrem à China por ajuda contra coronavírus. El País, 25 mar. 2020. Disponível em: https://brasil.elpais.com/brasil/2020-03-25/desconfiados-de-bolso naro-governadores-recorrem-a-china-por-ajuda-contra-coronavirus.html. Acesso em: 14 maio 2020.

${ }^{42}$ CORONAVÍRUS: Prefeitos da Região Sul pedem ajuda à China. Prefeitura Municipal de Liberato Salzano. Disponivel em: https://liberatosalzano.rs.gov.br/noticia/visualizar/id/1272/?coronavirus-prefeitos-da-regiaosul-pedem-ajuda-a-china.html. Acesso em: 14 maio 2020.
} 
de imprensa que, sob requerimento do governo federal, a organização poderia trabalhar de forma mais direta com os estados brasileiros: "[...] a entidade deixou claro que, no passado, já estabeleceu operações específicas com os governadores estaduais do país, inclusive sobre febre amarela" ${ }^{43}$. Dessa forma, Ryan demonstra a instrumentalização da cooperação técnica e sua preocupação com uma paradiplomacia bem institucionalizada.

Dentre as ações internacionais de entes subnacionais no início da pandemia, a do Maranhão se destaca. O governador do estado, Flávio Dino, comprou 107 respiradores e 200 mil máscaras da China. O diferencial dessa compra foi a rota feita pelo carregamento, passando primeiro pela Etiópia para chegar a Guarulhos e, depois, seguir em um voo fretado para São Luís, no Maranhão. Tal roteiro se deu, majoritariamente, por dois motivos: primeiro, evitar passar a carga pelos Estados Unidos, uma vez que, recentemente, uma carga chinesa semelhante com destino ao Brasil acabou sendo retida nesse país; e, segundo, evitar o risco de retenção da carga pelo próprio Ministério da Saúde brasileiro.

Em março, o governo maranhense havia encomendado uma carga de respiradores de uma empresa de Santa Catarina, mas o governo federal bloqueou o negócio, dizendo que o manejo desses instrumentos deveria obedecer [a] critérios federais. O Ministério da Saúde tem tentado centralizar a distribuição de equipamentos médicos com base na necessidade de cada região, o que vem gerando conflitos com estados ${ }^{44}$.

A ação governamental de Dino é tida como legítima tendo em vista as normas jurídicas aqui já expostas. Porém, ela explicita a falta de coordenação e cooperação entre os entes federativos e o governo federal, bem como os riscos políticos e jurídicos de a sobreposição de normas resultar em uma possível crise institucional.

A falta de colaboração e amparo do governo federal é observada também no estado de São Paulo, que tem enfrentado problemas para lidar com estratégias eficazes a fim de frear a transmissão da COVID-19 em regiões de maior vulnerabilidade social. Já a prefeitura do município de São Paulo fez um mapeamento internacional das ações de enfrentamento da doença, dos principais organismos internacionais e de redes municipais de cooperação internacional da qual a cidade faz parte a fim de obter um panorama internacional para tecer estratégias. Nos documentos, a Secretaria de Relações Internacionais da prefeitura de São

\footnotetext{
${ }^{43} \mathrm{CHADE}$, Jamil. OMS se diz pronta a ajudar estados. Mas governo federal precisa solicitar. Notícias UOL, 06 maio 2020. Disponível em: https://noticias.uol.com.br/colunas/jamil-chade/2020/05/06/ oms-se-diz-pronta-a-ajudar-estados-brasileiros-se-houver-pedido-do-governo.htm. Acesso em: 15 maio 2020.

${ }^{44}$ CHARLEAUX, João Paulo. A diplomacia paralela da compra de respiradores pelo Maranhão. Nexo, 22 abr. 2020. Disponível em: https://www.nexojornal.com.br/expresso/2020/04/21/A-diplomacia-paralela-da-c ompra-de-respiradores-pelo-Maranh\%C3\%A3o. Acesso em: 14 maio 2020.
} 
Paulo reproduz as recomendações e oportunidades desenvolvidas no âmbito das redes de cidades que podem ser exemplos para ações paradiplomáticas futuras, mas deixa claro que as informações apresentadas não representam a opinião da Secretaria, servindo apenas para monitorar as práticas que vêm sendo adotadas em todo o mundo ${ }^{45}$.

Por fim, percebe-se que o federalismo cooperativo não vem sendo exercido da melhor forma e que existe uma insuficiência do Estado em responder às necessidades e articular respostas que pode vir a ser suprimida pela paradiplomacia. E ainda, existe uma compatibilidade das ações paradiplomáticas realizadas com os interesses nacionais expressos na constituição, nos acordos e tratados internacionais firmados pelo Brasil, como já exposto.

\section{Considerações finais}

No federalismo, é papel do presidente da República ser o articulador das políticas públicas, coordenando a resposta da crise e respeitando a autonomia dos estados e municípios. Entretanto, na crise sanitária instaurada atualmente, o governo federal tem dificuldades de implementar um plano nacional para o enfrentamento da pandemia e também de vacinação, entrando em choque com o STF, a Câmara dos Deputados e governadores.

Desta forma, ficou a cargo dos estados e municípios a liderança na tomada de decisões acerca do combate e resposta à COVID-19. Entretanto, mesmo seguindo as diretrizes corretas, principalmente as recomendações de organismos internacionais como a OMS, os entes federativos sofrem problemas para estruturar estratégias robustas de enfrentamento e saída da crise, como projetos de longo prazo com amplo alcance setorial. Um plano de ação apresentado pelo Executivo nacional serviria como orientação para a atuação dos estados e municípios, trazendo coesão aos esforços coletivos e uma resposta eficiente do Estado brasileiro.

Em levantamento realizado pelo instituto de pesquisa Ideia Big Data nos dias 2 e 9 de abril de 2020, o desempenho dos governadores nas primeiras semanas da pandemia foi aprovado por $55 \%$ da população $0^{46}$ - sendo o governador Dino, do Maranhão, o líder em publicações sobre o tema no Twitter. Enquanto isso, a aprovação do presidente caiu de $57,5 \%$, em fevereiro de 2019 , para $39,2 \%$, em maio de 2020, segundo pesquisa realizada pela Confederação Nacional do Transporte (CNT) com o Instituto MDA divulgada no dia 12 de maio de 2020. Então, não é de

\footnotetext{
${ }^{45}$ ACESSE todas as edições do mapeamento de ações internacionais de enfrentamento ao coronavírus. Cidade de São Paulo - Relações Internacionais. Disponível em: https://www.prefeitura.sp.gov.br/cidade/ secretarias/relacoes_internacionais/noticias/?p=300094. Acesso em: 08 março 2021.

${ }^{46}$ Decompondo o porcentual: 24\% Ótimo; 31\% Bom; 26\% Regular; 7\% Ruim; 6\% Péssimo; e 6\% Não sei.
} 
se ignorar essa vertente política da paradiplomacia. Desta forma, também se percebe que a esfera internacional contribui para o alcance de objetivos domésticos, para os quais muitas vezes não há contribuição do Estado.

Conclui-se que a paradiplomacia no Brasil ainda é uma política restrita e pouco conhecida pela maioria da população, apesar de estar difundida e presente em maior parte do território nacional. Indo mais além, Laura Waisbich a classifica como uma área insuficientemente estudada e explorada. Ademais: "Distintos cientistas políticos têm apontado para os crescentes conflitos federativos no governo Bolsonaro; que não são uma novidade em nosso sistema político, mas que atingem hoje níveis elevados" ${ }^{47}$. E tal situação se daria devido à pandemia, responsável por outros inúmeros agravamentos de tendências, como o desemprego e a precarização do trabalho, entre outros.

Por fim, ficou nítida a importância dos tratados internacionais e das organizações internacionais para aclarar e efetivar os direitos no Brasil, inclusive o direito à saúde. Como ocorrera anteriormente no caso do amianto, as convenções internacionais e as recomendações de uma organização internacional (a OMS) foram critérios determinantes na apreciação da constitucionalidade das leis estaduais e municipais pelo Judiciário. E, novamente, os estados e municípios tomaram medidas mais protetivas da segurança e da saúde da população, em conformidade com as convenções externas, e algumas vezes recorreram a ações paradiplomáticas.

\section{REFERÊNCIAS}

ABRANTES, Vinicius Villani. Brasil e a "diplomacia da saúde”: um recorte temporal da atuação do estado na pandemia de COVID-19. Boletim de Conjuntura, ano II, vol. 4, n. 10, Boa Vista, 2020.

ABREU, Gustavo de Souza. Efeitos político-jurídicos da não institucionalizada paradiplomacia no Brasil. Revista Brasileira de Políticas Públicas, Brasília, v. 3, n. 2, p. 66-79, 2013. Disponível em: https://www.publicacoes.uniceub.br/RBPP/article/download/1803/pdf_1. https://doi. org/10.5102/rbpp.v3i2.1803.

ACESSE todas as edições do mapeamento de ações internacionais de enfrentamento ao coronavírus. Cidade de São Paulo - Relações Internacionais. Disponível em: https://www. prefeitura.sp.gov.br/cidade/secretarias/relacoes_internacionais/noticias/?p=300094. Acesso em: 08 março 2021.

ARRETCHE, Marta. Federalismo e políticas sociais no Brasil: problemas de coordenação e autonomia. São Paulo Perspectiva, São Paulo, v. 18, n. 2, p. 17-26, abr./jun. 2004. Disponível em: https://www.scielo.br/pdf/spp/v18n2/a03v18n2.pdf. https://doi.org/10.1590/S010288392004000200003.

${ }^{47}$ CHARLEAUX, João Paulo. op. cit. 
BENITES, Afonso. Desconfiados de Bolsonaro, governadores recorrem à China por ajuda contra coronavírus. El País, 25 mar. 2020. Disponível em: https://brasil.elpais.com/ brasil/2020-03-25/desconfiados-de-bolsonaro-governadores-recorrem-a-china-por-ajudacontra-coronavirus.html. Acesso em: 14 maio 2020.

BORGES, Daniel Damásio. Conflito federativo e crise sanitária - a prevalência do direito à saúde. F3 Notícias. Disponível em: https://www.f3noticias.com.br/conflito-federativo-e-crise-sanitariaa-prevalencia-do-direito-a-saude-por-daniel-damasio-borges/. Acesso em: 14 maio 2020.

BORGES, Daniel Damásio. O alcance dos tratados sobre os direitos sociais no direito brasileiro. 1. ed. Curitiba: Editora Appris, 2019.

BUSS, Paulo M. De pandemias, desenvolvimento e multilateralismo. Le Monde Diplomatique Brasil, 03 abr. 2020. Disponível em: https://diplomatique.org.br/de-pandemiasdesenvolvimento-e-multilateralismo/. Acesso em: 14 maio 2020.

CHADE, Jamil. OMS se diz pronta a ajudar estados. Mas governo federal precisa solicitar. Notícias UOL, 06 maio 2020. Disponível em: https://noticias.uol.com.br/colunas/jamilchade/2020/05/06/oms-se-diz-pronta-a-ajudar-estados-brasileiros-se-houver-pedido-dogoverno.htm. Acesso em: 15 maio 2020.

CHARLEAUX, João Paulo. A diplomacia paralela da compra de respiradores pelo Maranhão. Nexo, 22 abr. 2020. Disponível em: https://www.nexojornal.com.br/expresso/2020/04/21/Adiplomacia-paralela-da-compra-de-respiradores-pelo-Maranh\%C3\%A3o. Acesso em: 14 maio 2020.

CORONAVÍRUS: Prefeitos da Região Sul pedem ajuda à China. Prefeitura Municipal de Liberato Salzano. Disponível em: https://iberatosalzano.rs.gov.br/noticia/visualizar/ $\mathrm{id} / 1272 /$ ? coronavirus-prefeitos-da-regiao-sul-pedem-ajuda-a-china.html. Acesso em: 14 maio 2020 .

CRIVELLA negocia e aviões da FAB podem buscar novos respiradores na China. Notícias UOL, 30 mar. 2020. Disponível em: https://noticias.uol.com.br/cotidiano/ultimasnoticias/2020/03/31/crivella-negocia-e-avioes-da-fab-podem-buscar-novos-respiradoresna-china.htm. Acesso em: 15 maio 2020.

DEL HUERTO ROMERO, Maria. Poder local y relaciones internacionales en contextos de integración regional: el caso de la red de mercociudades y la reunion especializada de municípios e intendencias: Grupo Mercado Comum. In: VIGEVANI, Tullo; WANDERLEY, Luiz Eduardo W.; BARRETO, Maria Inês; MARIANO, Marcelo Passini (Orgs.). A dimensão subnacional e as relações internacionais. 1. ed. São Paulo: Editora UNESP; Bauru: EDUSC, 2004.

DISTRITO RELAÇÕES GOVERNAMENTAIS. Cenários e Tendências. Disponível em: http:// distritorelgov.com/analisepolitica/. Acesso em: 16 maio 2020.

FOLHA informativa - COVID-19 (doença causada pelo novo coronavírus). OPAS Brasil, 12 fev. 2021. Disponível em: https://www.paho.org/bra/index.php?option=com_content\& view=article\&id=6101: covid19\&Itemid=875\#datas-noticificacoes. Acesso em: 16 fev. 2021. 
COVID-19: parâmetros internacionais, federalismo e atuação dos estados e municípios

GUEDES, Jozivan. Biopolítica e normatividade: duas abordagens filosóficas acerca da pandemia da COVID-19 a partir de Agamben e Habermas. Voluntas: revista internacional de filosofia, v. 11, e8, p. 1-9, 2020. Disponível em: https://periodicos.ufsm.br/voluntas/article/ download/43663/pdf. https://doi.org/10.5902/2179378643663.

HARARI, Yuval Noah. Na batalha contra o coronavírus, faltam líderes à humanidade. São Paulo: Breve Companhia, 2020.

HOCKING, Brian. Regionalismo: uma perspectiva das relações internacionais. In: VIGEVANI, Tullo; WANDERLEY, Luiz Eduardo W.; BARRETO, Maria Inês; MARIANO, Marcelo Passini (Orgs.). A dimensão subnacional e as relações internacionais. 1. ed. São Paulo: Editora UNESP; Bauru: EDUSC, 2004.

LINDNER, Julia. Reprovação ao governo Bolsonaro sobe 12 pontos e chega à taxa recorde de 43\%. O Estado de S. Paulo, São Paulo, 12 maio 2020. Disponível: https://politica.estadao.com. $\mathrm{br} /$ noticias/geral,avaliacao-negativa-do-governo-bolsonaro-supera-a-positiva-na-pandemiado-coronavirus-aponta-cntmda,70003300192. Acesso em: 18 maio 2020.

MIGUEL, Vinícius Valentin Raduan. Coronavírus, desarmonia federativa e estratégias democráticas para a pandemia. Justificando, 13 abr. 2020. Disponível em: http://www. justificando.com/2020/04/13/coronavirus-desarmonia-federativa-e-estrategias-democraticaspara-a-pandemia/. Acesso em: 17 abr. 2020.

MINISTÉRIO DA SAÚDE - MS. Plano de Contingência Nacional para Infecção Humana pelo novo coronavírus COVID-19. Brasília-DF: Secretaria de Vigilância em Saúde, 2020. Disponível em: https://portalarquivos.saude.gov.br/images/pdf/2020/marco/25/Livreto-Plano-deContingencia-5-Corona2020-210x297-16mar.pdf. Acesso em: Acesso em: 16 fev. 2021.

MINISTÉRIO DA SAÚDE - MS. Protocolo de Manejo Clínico do coronavírus (COVID-19) na Atenção Primária à Saúde. Versão 9. Brasília-DF: Secretaria de Atenção Primária à Saúde (SAPS), 2020. Disponível em: https://portalarquivos2.saude.gov.br/images/pdf/2020/ May/05/20200504-ProtocoloManejo-ver09.pdf. Acesso em: 16 fev. 2021.

OMS afirma que COVID-19 é agora caracterizada como pandemia. OPAS Brasil, 11 mar. 2020. Disponível em: https://www.paho.org/bra/index.php?option=com_ content $\&$ view=article $\&$ id=6120:oms-afirma-que-covid-19-e-agora-caracterizada-comopandemia\&Itemid=812. Acesso em: 18 maio 2020.

OMS declara emergência de saúde pública de importância internacional por surto de novo coronavírus. OPAS Brasil, 30 jan. 2020. Disponível em: https://www.paho.org/bra/index. php?option=com_content $\&$ view $=$ article $\&$ id $=6100$ :oms-declara-emergencia-de-saudepublica-de-importancia-internacional-em-relacao-a-novo-coronavirus\&Itemid $=812$. Acesso em: 16 fev. 2021.

ORGANIZAÇÃO DAS NAÇÕES UNIDAS - ONU. Declaração Universal dos Direitos Humanos. Adotada e proclamada pela Assembleia Geral das Nações Unidas (resolução 217 A III) em 10 de dezembro 1948. Disponível em: https://www.unicef.org/brazil/declaracaouniversal-dos-direitos-humanos. Acesso em: 16 fev. 2021. 
ORGANIZAÇÃO PAN-AMERICANA DA SAÚDE - OPAS. Regulamento Sanitário Internacional (RSI). Disponível em: https://www.paho.org/bra/index.php?option=com_con tent\&view $=$ article\&id=5847:regulamento-sanitario-internacional-rsi\&Itemid=812. Acesso em: 16 fev. 2021.

PECEQUILO, Cristina Soreanu. Aspectos das eleições nos EUA e do governo Trump frente à COVID-19. In: ENCONTRO NACIONAL DE ESTUDANTES DE RELAÇÕES INTERNACIONAIS, 25., 2020, Salvador-BA. Disponível em: https://www.youtube.com/ watch? $\mathrm{v}=\mathrm{A}-014 \mathrm{otDfxQ}$. Acesso em: 19 maio 2020.

PROGRAMA DAS NAÇÕES UNIDAS PARA O DESENVOLVIMENTO. Plataforma Agenda 2030. Disponível em: http://www.agenda2030.com.br/. Acesso em: 16 fev. 2021.

RIBEIRO, Maria Clotilde Meirelles. Globalização e novos atores: a paradiplomacia das cidades brasileiras. Salvador: Editora da UFBA, 2009.

SAIBA quais as medidas do Governo de SP para o combate ao coronavírus. Portal do Governo, 17 mar. 2020. Disponível em: https://www.saopaulo.sp.gov.br/spnoticias/saiba-quais-asmedidas-do-governo-de-sp-para-o-combate-ao-coronavirus-2/. Acesso em: 18 maio 2020.

SALOMÓN, Mónica; NUNES, Carmen. A ação externa dos governos subnacionais no Brasil: os casos do Rio Grande do Sul e de Porto Alegre. Um estudo comparativo de dois tipos de atores mistos. Contexto Internacional Rio de Janeiro, vol. 29, n. 1, p. 99-147, jan./jun. 2007. Disponível em: https://www.scielo.br/pdf/cint/v29n1/a04v29n1.pdf. https://doi.org/10.1590/ S0102-85292007000100004.

A SOLIDARIEDADE é a única cura. Entrevista com Jürgen Habermas. Revista IHU On-Line, 13 abr. 2020. Disponível em: http://www.ihu.unisinos.br/78-noticias/597983-a-solidariedadee-a-unica-cura-entrevista-com-juergen-habermas. Acesso em: $10 \mathrm{dez} .2020$.

TRUMP suspende financiamento dos Estados Unidos à OMS. O Estado de S. Paulo, São Paulo, 14 abr. 2020. Disponível em: https://internacional.estadao.com.br/noticias/geral,trumpsuspende-financiamento-dos-estados-unidos-a-oms,70003271069. Acesso em: 07 maio 2020.

VIGEVANI, Tullo; PRADO, Débora Figueiredo B. Ações e problemas para a paradiplomacia no Brasil. In: BLANES SALA, José; GASPAROTO, Ana Lúcia (Orgs.). Relações internacionais: polaridades e novos/velhos temas urgentes. Marília-SP: Editora UNESP - Oficina Universitária, 2010.

XADREZ Verbal e Atila Iamarino. Especial coronavírus \#02. Xadrez Verbal, 24 mar. 2020. Disponível em: https://xadrezverbal.com/2020/03/24/xadrez-verbal-e-atila-iamarinoespecial-coronavirus-02/. Acesso em: 05 abr. 2020.

ORGANIZAÇÃO INTERNACIONAL DO TRABALHO - OIT. C162 - Utilização do Amianto com Segurança. Disponível em: https://www.ilo.org/brasilia/convencoes/WCMS_236241/ lang--pt/index.htm. Acesso em: 16 fev. 2021. 
COVID-19: parâmetros internacionais, federalismo e atuação dos estados e municípios

Gabriela Fideles Silva - graduanda em Relações Internacionais na Universidade Estadual Paulista "Júlio de Mesquita Filho" (UNESP). Membro do Projeto de Extensão Universitária "Cidades Saudáveis e Sustentáveis"; coordenadora do projeto "As Relações Internacionais e o Novo Coronavírus", do Laboratório de Relações Internacionais (LabRI). Franca/SP, Brasil. E-mail: gabriela.fideles@unesp.br

Vinícius César Guimarães - graduando em Relações Internacionais na Universidade Estadual Paulista "Júlio de Mesquita Filho" (UNESP). Membro do Projeto de Extensão Universitária "Cidades Saudáveis e Sustentáveis"; coordenador do projeto "As Relações Internacionais e o Novo Coronavírus”, do Laboratório de Relações Internacionais (LabRI). Franca/SP, Brasil. E-mail: vinicius.guimaraes@unesp.br 